\title{
Intrapartum magnesium sulfate and need for intensive delivery room resuscitation
}

\author{
Dany E Weisz, ${ }^{1}$ Sandesh Shivananda, ${ }^{2}$ Elizabeth Asztalos, ${ }^{1,3}$ Wendy Yee, ${ }^{4}$ \\ Anne Synnes, ${ }^{5}$ Shoo K Lee, ${ }^{3}$ Prakesh S Shah, ${ }^{3,6}$ on behalf of the Canadian \\ Neonatal Network
}

- Additional material is published online only. To view please visit the journal online (http://dx.doi.org/10.1136/ archdischild-2013-305884).

1 Department of Newborn and Developmental Paediatrics, Sunnybrook Health Sciences Centre, Toronto, Canada ${ }^{2}$ Department of Paediatrics, McMaster Children's Hospital, Hamilton, Canada

${ }^{3}$ Department of Paediatrics, University of Toronto, Toronto, Canada

${ }^{4}$ Department of Paediatrics, University of Calgary, Calgary, Canada

${ }^{5}$ Department of Paediatrics, University of British Columbia, Vancouver, Canada

${ }^{6}$ Institute of HPME, University of Toronto, Toronto, Canada

\section{Correspondence to}

Dr Prakesh S Shah,

Department of Paediatrics,

University of Toronto, Staff

Neonatologist, Mount Sinai

Hospital, 775A- 600 University

Avenue, Toronto, Ontario,

Canada M5G 1X5;

pshah@mtsinai.on.ca

Received 20 December 2013

Revised 4 August 2014

Accepted 26 August 2014

Published Online First

17 September 2014

\section{ABSTRACT}

Objective To evaluate the association of intrapartum magnesium sulfate for fetal neuroprotection $\left(\mathrm{MgSO}_{4}-\mathrm{FN}\right)$ with the delivery room resuscitation and neonatal outcomes of preterm infants in an era of minimisation of invasive mechanical ventilation.

Design Retrospective cohort study.

Setting Neonatal intensive care units in the Canadian Neonatal Network.

Patients and intervention Preterm infants $\left(23^{\circ}\right.$ to $31^{6}$ weeks gestational age) born in 2011 or 2012 .

Resuscitation requirements and neonatal outcomes were compared between infants exposed and unexposed to intrapartum $\mathrm{MgSO}_{4}-\mathrm{FN}$.

Main outcome measures The primary outcome was a composite outcome of 'intensive resuscitation', defined as the need for intubation and ventilation or chest compressions or epinephrine administration in the delivery room. Secondary outcomes included mortality and major neonatal morbidities.

Results Of 6015 eligible infants, 1387 (23.1\%) were exposed to intrapartum $\mathrm{MgSO}_{4}$-FN. Significantly fewer $\mathrm{MgSO}_{4}-\mathrm{FN}$ infants $(41.0 \%$ vs $44.6 \%, p=0.02$ ) required intensive resuscitation. However, after adjustment for confounders, this difference was no longer significant (adjusted OR (AOR) $0.88 ; 95 \% \mathrm{Cl} 0.66$ to 1.17). Infants exposed to $\mathrm{MgSO}_{4}-\mathrm{FN}$ had decreased odds of death (AOR 0.61; 95\% Cl 0.40 to 0.94), but there was no difference in neonatal morbidities compared with the unexposed infants.

Conclusions Intrapartum $\mathrm{MgSO}_{4}$ for fetal neuroprotection was not associated with an increased need for intensive delivery room resuscitation in this cohort of preterm infants.

\section{INTRODUCTION}

In 2010 and 2011, the Royal College of Obstetricians and Gynaecologists, American College of Obstetricians and Gynaecologists, and Society of Obstetricians and Gynaecologists of Canada (SOGC) published guidelines recommending the administration of intrapartum magnesium sulfate $\left(\mathrm{MgSO}_{4}\right)$ to pregnant women at imminent risk of early preterm birth for fetal neuroprotection. ${ }^{1-3}$ These recommendations were based on five randomised placebo-controlled trials (RCT) and three meta-analyses that reported a reduction in the risk of cerebral palsy or gross motor dysfunction in survivors. $^{4-11}$

The effect of intrapartum $\mathrm{MgSO}_{4}$ on the need for neonatal resuscitation has been a source of

\section{What is already known on this topic}

Intrapartum magnesium sulfate for the neuroprotection of preterm infants is recommended based on trials conducted during an era of routine delivery room intubation. Its effect on the need for resuscitation under contemporary delivery room care practices that aim to avoid invasive mechanical ventilation is unknown.

\section{What this study adds}

Exposure to intrapartum magnesium sulfate is not associated with an increased need for intensive delivery room resuscitation in preterm infants under current delivery room care practices.

concern, based on the risk of hypotonia, hypotension and respiratory depression associated with its administration. ${ }^{12-17}$ Previous studies have reported that $\mathrm{MgSO}_{4}$-exposed infants did not have increased need for delivery room resuscitation ${ }^{79}$ and no correlation has been identified between cord blood magnesium concentrations and the need for intensive resuscitation. ${ }^{18}$ However, these trials were conducted in an era (1995-2005) of routine endotracheal intubation and surfactant administration for extremely preterm infants. ${ }^{19}$

Intubation and mechanical ventilation for preterm infants has evolved into a selective practice for those who have inadequate respiratory effort or demonstrate respiratory insufficiency after treatment with nasal continuous positive airway pressure. ${ }^{20-23}$ Thus, intrapartum $\mathrm{MgSO}_{4}$ administration may have different implications under current resuscitation practices where strategies are used to avoid invasive mechanical ventilation. While a single-centre cohort study reported no difference in the need for delivery room resuscitation in $\mathrm{MgSO}_{4}$-exposed versus unexposed preterm infants, ${ }^{24}$ contemporary population-level evaluations of the effect of $\mathrm{MgSO}_{4}$ exposure on the need for respiratory support have not been reported.

The objective of this study was to evaluate the association of intrapartum $\mathrm{MgSO}_{4}$ for fetal neuroprotection with the delivery room resuscitation and neonatal outcomes of preterm infants. We hypothesised that exposure to intrapartum $\mathrm{MgSO}_{4}$ would 
be associated with an increased need for intensive resuscitation, defined as intubation and ventilation, or chest compressions or epinephrine administration, in the delivery room.

\section{METHODS AND STUDY POPULATION}

The Canadian Neonatal Network (CNN) maintains a national database for the purpose of outcomes evaluation, benchmarking and quality improvement. Data from all eligible neonatal intensive care unit (NICU) admissions are collected and submitted by trained research assistants who abstract relevant data from the charts at each participating centre after institutional approval (either from a local Research Ethics Board or an institutional quality improvement committee). Details of CNN data collection and data management have been previously published. ${ }^{25}$ Data from all eligible infants born $23^{0}$ to $31^{6}$ weeks gestational age (GA) admitted to CNN NICUs between 1 January 2011 and 31 December 2012, were used for this study.

\section{Study design and outcomes}

This study was a retrospective cohort study. Infants whose mothers received intrapartum $\mathrm{MgSO}_{4}$ for fetal neuroprotection prior to delivery were considered exposed to $\mathrm{MgSO}_{4}$. Infants with major congenital anomalies and those who were moribund on admission (ie, a physician, in consultation with the parents, had made an explicit decision not to provide life support at the time of birth) were excluded from the analysis. It was decided, a priori, to exclude infants whose $\mathrm{MgSO}_{4}$ exposure status was missing. The primary outcome was a composite outcome of 'intensive resuscitation', defined as the need for intubation and ventilation, or chest compressions or epinephrine administration, in the delivery room. Secondary outcomes included neonatal mortality, severe neonatal morbidities (retinopathy of prematurity (ROP) $\geq$ stage 3 , necrotising enterocolitis (NEC) $\geq$ stage 2, bronchopulmonary dysplasia (BPD), grade 3 or 4 intraventricular hemorrhage or periventricular leukomalacia, late-onset sepsis) and a composite outcome defined as neonatal mortality or severe neonatal morbidity. A subgroup analysis was planned to evaluate the outcomes in infants $\leq 28$ weeks and $>28$ weeks GA, given the previously demonstrated benefit of $\mathrm{MgSO}_{4}$ in the lower GA group ${ }^{7}$ and the perceived increased risk of adverse effects of $\mathrm{MgSO}_{4}$ in this group.

Fetal neuroprotection may have been the actual indication for intrapartum $\mathrm{MgSO}_{4}$ in infants whose indication was recorded as 'unknown', and so we performed sensitivity analyses imputing these infants as having been exposed to $\mathrm{MgSO}_{4}$ for fetal neuroprotection. We also examined the characteristics of infants exposed to intrapartum $\mathrm{MgSO}_{4}$ for pre-eclampsia and tocolysis, and performed sensitivity analyses comparing the outcomes of all infants exposed to $\mathrm{MgSO}_{4}$ (for any indication) versus unexposed infants.

\section{Variable definitions}

Study variables were defined according to the CNN manual. ${ }^{26}$ GA was defined as the best estimate based on the date of in vitro fertilisation, early ultrasound, obstetric history and examination or by paediatric estimate, in that order. For infants exposed to intrapartum $\mathrm{MgSO}_{4}$, the indication for administration was recorded as one of: fetal neuroprotection, other (tocolysis or pre-eclampsia/eclampsia), or unknown, based on the information available in the infant's chart. ${ }^{26}$ Data on immediate resuscitation details within the first $30 \mathrm{~min}$ after birth were recorded for all infants with respect to minimal support to extensive resuscitation. For outborn infants (defined as infants delivered in Level 1 or Level 2 centres), resuscitation details were extracted from neonatal transport services documentation. All units followed the Canadian modification of the Neonatal Resuscitation Program. ${ }^{27}$ Neonatal outcome definitions were standardised. Intraventricular haemorrhage was defined according to the criteria of Papile $e t a l^{28}$ from the worst findings on head ultrasound during the infant's stay in the NICU. Periventricular echogenicity or leukomalacia was detected based on ultrasound or MRI findings. ROP was classified according to the international classification. ${ }^{29}$ NEC was defined according to Bell's criteria (stage 2 or higher). ${ }^{30}$ BPD was defined as the need for any form of respiratory support (oxygen or positive pressure support) at 36 weeks corrected GA or at the time of discharge to level 2 NICUs. ${ }^{31}$ Late-onset sepsis was defined as the presence of a pathogenic organism in either a blood or cerebrospinal fluid culture in a symptomatic infant after the third day of life.

\section{Statistical analysis}

Descriptive statistical methods were applied to describe the study population. Infant characteristics and outcomes were compared between $\mathrm{MgSO}_{4}$ and $\mathrm{No}-\mathrm{MgSO}_{4}$ groups using the $\chi^{2}$ test for categorical variables and the $t$ test or Wilcoxon-Rank Sum test for continuous variables. To further determine the effect of $\mathrm{MgSO}_{4}$, we estimated ORs of receiving intensive resuscitation and of the neonatal outcomes using multiple logistic regression models with a generalised estimating equation approach to account for the correlated data within each NICU site (or site effect). This approach uses weighted combinations of observations to extract the appropriate amount of information from correlated data. ${ }^{32}$ The covariates included in the full model were GA, gender, small for gestational age (SGA), outborn status, chorioamnionitis, mode of delivery, antenatal steroid use and multiple gestation. Data management and statistical analyses were performed using SAS V.9.2 (SAS Institute, Cary, North Carolina, USA).

\section{RESULTS}

There were 6759 infants with a GA between $23^{0}$ and $31^{6}$ weeks admitted to all 30 NICUs in the CNN during the study period. Of these infants, we excluded $350(5.2 \%)$ who were moribund or had major congenital anomalies, and 394 (6.4\%) infants with missing $\mathrm{MgSO}_{4}$ information (figure 1). The remaining 6015 infants were included in the analysis. Of these, 2147 (35.7\%) infants were exposed to intrapartum $\mathrm{MgSO}_{4}$ and 3868 (64.3\%) were unexposed. Of the exposed infants, $\mathrm{MgSO}_{4}$ was administered for fetal neuroprotection in 1387 infants (magnesium sulfate-fetal neuroprotection group $\left.\left(\mathrm{MgSO}_{4}-\mathrm{FN}\right)\right)$, for preeclampsia or tocolysis in 214 infants $\left(\mathrm{MgSO}_{4}\right.$ - other indication group), and the indication for administration was unknown in 546 infants (magnesium sulfate-indication unknown group $\left.\left(\mathrm{MgSO}_{4}-\mathrm{IU}\right)\right)$.

Baseline characteristics revealed the $\mathrm{MgSO}_{4}-\mathrm{FN}$ infants had lower GA, lower birth weight and were more likely to have received antenatal corticosteroids (ACS), be SGA and inborn compared with unexposed infants (table 1). There was no significant difference in the proportion of infants with $5 \mathrm{~min}$ Apgar score $<7$ or SNAP-II score $>20$ (table 2). Significantly fewer $\mathrm{MgSO}_{4}-\mathrm{FN}$ infants $(41.0 \%$ vs $44.6 \%, \mathrm{p}=0.02)$ required intensive resuscitation (intubation and ventilation or chest compressions or epinephrine) (table 3).

After adjustment for confounders, the $\mathrm{MgSO}_{4}-\mathrm{FN}$ infants had lower odds of death compared with the unexposed infants, but there was no significant difference in the odds of intensive resuscitation, severe neonatal morbidities or the composite outcome (table 3). In the subgroup analyses, $\mathrm{MgSO}_{4}$-exposed infants of 


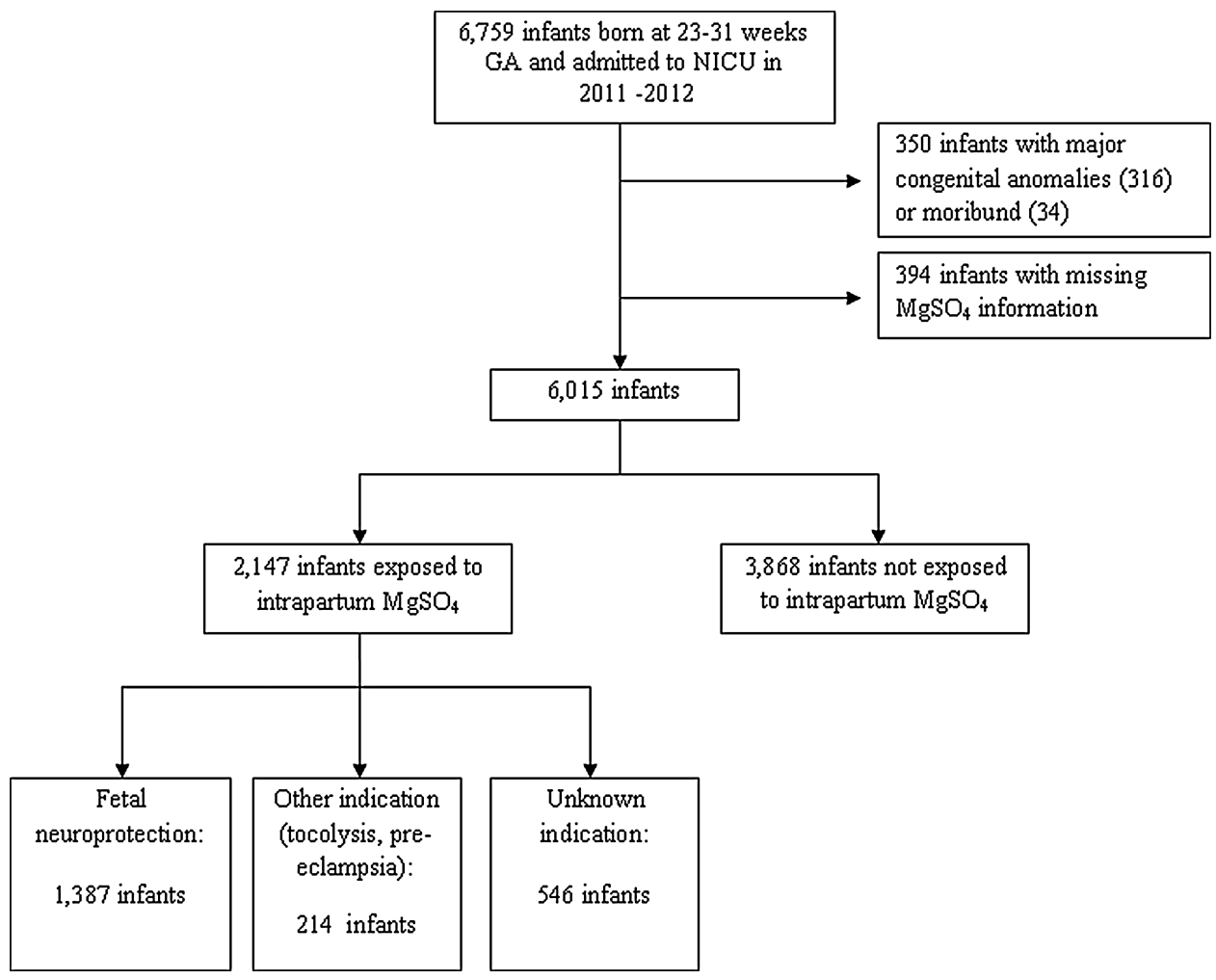

Figure 1 Study algorithm. CNN, Canadian Neonatal Network; NICUs, neonatal intensive care units; GA, gestational age; $\mathrm{MgSO}_{4}$, magnesium sulfate.

23-28 weeks GA had increased BPD but reduced mortality of borderline significance, and there were no other statistically significant differences in neonatal outcomes in either subgroup (tables 4 and 5). Subgroup interaction testing revealed that these GA subgroup differences were not statistically significant.
Compared with the $\mathrm{MgSO}_{4}-\mathrm{FN}$ group, the $\mathrm{MgSO}_{4}$-other indication and $\mathrm{MgSO}_{4}$-IU infants were slightly more mature $(28.0 \pm 2.3$ vs $28.5 \pm 2.0$ and $28.4 \pm 2.1$ weeks GA, respectively, both $\mathrm{p}<0.01)$, had less chorioamnionitis $(23.3 \%$ vs $4.1 \%$ and $14.5 \%$, respectively, both $\mathrm{p}<0.01)$, and were more likely to be

Table 1 Patient characteristics

\begin{tabular}{|c|c|c|c|c|}
\hline & $\mathrm{MgSO}_{4}$ for fetal neuroprotection $(n=1387)$ & $\mathrm{No} \mathrm{MgSO}_{4}(n=3868)$ & Difference $(95 \% \mathrm{CI})$ & p Value* \\
\hline Gestational age, weeks, mean (SD) & $28.0(2.3)$ & $28.3(2.3)$ & $-0.3(-0.5$ to -0.2$)$ & $<0.01$ \\
\hline Birth weight, g, mean (SD) & $1160(374)$ & $1232(402)$ & $-72(-95$ to -48$)$ & $<0.01$ \\
\hline Birth weight $<1000 \mathrm{~g}, \mathrm{n}(\%)$ & $526(37.9)$ & $1207(31.2)$ & 6.7 (3.8 to 9.2$)$ & $<0.01$ \\
\hline Birth weight $<1500 \mathrm{~g}, \mathrm{n}(\%)$ & $1113(80.2)$ & $2845(73.6)$ & $6.6(4.1$ to 9.2$)$ & $<0.01$ \\
\hline GA group, $n(\%)$ & & & & $<0.01$ \\
\hline $22-28$ weeks & $731(52.7)$ & $1813(46.9)$ & $5.8(2.8$ to 8.9$)$ & \\
\hline 29-31 weeks & $656(47.3)$ & $2055(53.1)$ & $-5.8(-8.9$ to -2.8$)$ & \\
\hline Female, n (\%) & $623(44.9)$ & $1709(44.2)$ & $0.7(-3.8$ to 2.3$)$ & 0.64 \\
\hline SGA (BW <10\%), n (\%) & $147(10.6)$ & $273(7.1)$ & 3.5 (1.7 to 5.4$)$ & $<0.01$ \\
\hline Outborn, n (\%) & $81(5.8)$ & $714(18.5)$ & $-12.7(-14.0$ to -11.0$)$ & $<0.01$ \\
\hline Chorioamnionitis, n (\%) & $265(23.3)$ & $569(20.8)$ & $2.4(-0.5$ to 5.3$)$ & 0.09 \\
\hline Caesarean, n (\%) & $766(55.3)$ & $2196(56.9)$ & $-1.6(-4.7$ to 1.4$)$ & 0.29 \\
\hline Antenatal corticosteroids, n (\%) & $1342(97.1)$ & $3170(83.4)$ & 13.7 (12.3 to 15.2$)$ & $<0.01$ \\
\hline Maternal hypertension, n (\%) & $257(18.8)$ & $405(10.6)$ & $8.2(5.9$ to 10.5$)$ & $<0.01$ \\
\hline Multiple gestation, n (\%) & $429(30.9)$ & $1166(30.1)$ & $0.8(-2.0$ to 3.6$)$ & 0.58 \\
\hline ROM & & & & 0.13 \\
\hline$<24 \mathrm{~h}$ & $1063(78.2)$ & $2860(76.7)$ & $1.5(-1.1$ to 4.1$)$ & \\
\hline $24 \mathrm{~h}-1$ week & $175(12.9)$ & $463(12.4)$ & $0.5(-1.6$ to 2.5$)$ & \\
\hline$>1$ weeks & $121(8.9)$ & $404(10.8)$ & $-1.9(-3.8$ to 0.1$)$ & \\
\hline Infants GA established in first trimestert, n (\%) & $835(60.2)$ & $1896(49.0)$ & $11.2(8.2$ to 14.2$)$ & $<0.01$ \\
\hline
\end{tabular}


Table 2 Resuscitation outcomes

\begin{tabular}{|c|c|c|c|c|}
\hline & $\mathrm{MgSO}_{4}$ for fetal neuroprotection $(n=1387)$ & No $\mathrm{MgSO}_{4}(\mathrm{n}=3868)$ & Difference $(95 \% \mathrm{Cl})$ & p Value* \\
\hline Any resuscitation neededt, $\mathrm{n}(\%)$ & $1324(95.7)$ & $3624(93.7)$ & $2.0(0.7$ to 3.3$)$ & $<0.01$ \\
\hline CPAP only, $\mathrm{n}(\%)$ & $561(40.7)$ & $1165(30.5)$ & $10.2(7.2$ to 13.1$)$ & $<0.01$ \\
\hline Bag/mask or Neopuff ventilation, $\mathrm{n}(\%)$ & $781(56.6)$ & $2344(61.4)$ & $-4.8(-7.8$ to -1.7$)$ & $<0.01$ \\
\hline Intubation and ventilation, $\mathrm{n}(\%)$ & $557(40.4)$ & $1669(43.7)$ & $-3.3(-6.4$ to -0.3$)$ & 0.03 \\
\hline Chest compressions, n (\%) & $54(3.9)$ & $266(6.9)$ & $-3.0(-4.4$ to -1.7$)$ & $<0.01$ \\
\hline Epinephrine (ETT or IV), n (\%) & $26(1.9)$ & $119(3.1)$ & $-1.2(-2.1$ to -0.3$)$ & 0.02 \\
\hline Maximum $\mathrm{FiO}_{2}$, median (IQR) & $60(40-100)$ & $80(40-100)$ & $-20(-30$ to -10$)$ & $<0.01$ \\
\hline 5 min Apgar $<7, \mathrm{n}(\%)$ & $412(29.8)$ & 1205 (31.6) & $-1.8(-4.7$ to 1.0$)$ & 0.20 \\
\hline Surfactant use, n (\%) & $735(53.0)$ & $2163(55.9)$ & $-2.9(-6.0$ to 0.1$)$ & 0.06 \\
\hline SNAPII score $>20, n(\%)$ & $1086(79.3)$ & $3074(80.6)$ & $-1.3(-3.8$ to 1.2$)$ & 0.28 \\
\hline
\end{tabular}

exposed to maternal hypertension $(18.7 \%$ vs $81.3 \%$ and $42.2 \%$, respectively, both $\mathrm{p}<0.01)$ and be SGA $(10.6 \%$ vs $26.3 \%$ and $14.7 \%$, respectively, both $\mathrm{p}<0.01$ ) (see online supplementary table $\mathrm{S} 1$ ).

The $\mathrm{MgSO}_{4}$-IU and $\mathrm{MgSO}_{4}-\mathrm{FN}$ infants had similar delivery room resuscitation requirements, including intubation and ventilation $(37.4 \%$ vs $40.4 \%, p=0.28)$, chest compressions $(4.4 \%$ vs $3.9 \%, \mathrm{p}=0.60)$ and epinephrine $(1.5 \%$ vs $1.9 \%, \mathrm{p}=0.54)$ (see online supplementary table S2). When the $\mathrm{MgSO}_{4}-\mathrm{FN}$ and $\mathrm{MgSO}_{4}$-IU groups were combined $(\mathrm{n}=1933)$ and compared with the $\mathrm{MgSO}_{4}$-unexposed infants $(\mathrm{n}=3868)$, the $\mathrm{MgSO}_{4}$-exposed infants had lower mortality (AOR 0.62, 95\% CI 0.44 to 0.87$)$. There was no difference in the need for intensive resuscitation (AOR 0.88 , 95\% CI 0.69 to 1.13 ) or any other secondary outcome between the combined $\mathrm{MgSO}_{4}$-exposed group and the unexposed infants.

The $\mathrm{MgSO}_{4}$ - other indication group required less intubation and ventilation in the delivery room compared with the $\mathrm{MgSO}_{4}$-FN infants $(29.7 \%$ vs $40.4 \%, \mathrm{p}<0.01)$ and there were no differences in chest compressions or epinephrine administration (see online supplementary table S2). A sensitivity analysis comparing the neonatal outcomes of $\mathrm{MgSO}_{4}$-unexposed infants $(\mathrm{n}=3868)$ vs all $\mathrm{MgSO}_{4}$-exposed infants (fetal neuroprotection, pre-eclampsia, tocolysis and $\mathrm{IU}, \mathrm{n}=2147$ ) revealed that the inclusion of the $\mathrm{MgSO}_{4}$ - other indication group did not alter the neonatal outcomes (see online supplementary table S3).

\section{DISCUSSION}

In this large retrospective cohort study from the CNN, we identified that there was no difference in the need for intensive resuscitation in preterm infants exposed to $\mathrm{MgSO}_{4}$ for fetal neuroprotection, compared with unexposed infants. Although the physiological and pharmacological properties of magnesium support concerns about the potential for hypotonia and respiratory depression in preterm infants, ${ }^{12-17}$ the absence of such negative effects in our cohort is consistent with the results of several other studies. In the only RCT that reported on the need for delivery room resuscitation, there was no difference in the need for resuscitation between the $\mathrm{MgSO}_{4}$-exposed and unexposed (placebo) infants ${ }^{7}$ and a subsequent secondary analysis identified no correlation between cord blood magnesium concentrations and the need for intensive resuscitation. ${ }^{18}$ A Cochrane review reported no difference between treatment groups in the proportion of infants with a 5 min Apgar score $<7$. ${ }^{9}$

In this study, infants exposed to $\mathrm{MgSO}_{4}$ for fetal neuroprotection had a lower adjusted odds of death compared with the unexposed infants. Although the meta-analyses demonstrated a reduction in the risk of the combined outcome of cerebral palsy

Table 3 Univariate and multivariate analyses of outcomes for all infants

\begin{tabular}{|c|c|c|c|c|c|}
\hline & $\begin{array}{l}\mathrm{MgSO}_{4} \text { for fetal } \\
\text { neuroprotection }(n=1387)\end{array}$ & $\begin{array}{l}{\mathrm{No} \mathrm{MgSO}_{4}}_{(n=3868)}\end{array}$ & p Value & $\begin{array}{l}\text { Unadjusted } \\
\text { OR }(95 \% \mathrm{Cl})^{*}\end{array}$ & $\begin{array}{l}\text { Adjusted } \\
\text { OR }(95 \% \mathrm{Cl})^{*} \dagger\end{array}$ \\
\hline Intensive resuscitationf, n (\%) & $566(41.0)$ & $1702(44.6)$ & 0.02 & 0.87 (0.76 to 0.98$)$ & 0.88 (0.66 to 1.17$)$ \\
\hline Death, n (\%) & $98(7.1)$ & $367(9.5)$ & $<0.01$ & 0.73 (0.58 to 0.92 ) & 0.61 (0.40 to 0.94$)$ \\
\hline Bronchopulmonary dysplasia, n (\%) & $276(21.4)$ & $703(20.0)$ & 0.28 & 1.09 (0.93 to 1.18$)$ & 1.13 (0.92 to 1.38$)$ \\
\hline NEC stage $\geq 2, n(\%)$ & $83(6.0)$ & $197(5.1)$ & 0.20 & $1.19(0.91$ to 1.55$)$ & 0.99 (0.73 to 1.34$)$ \\
\hline Grade 3 or $4 \mathrm{IVH}$ or $\mathrm{PVL}, \mathrm{n}(\%)$ & $176(13.8)$ & $493(14.3)$ & 0.62 & 0.95 (0.79 to 1.15$)$ & 1.01 (0.76 to 1.34$)$ \\
\hline ROP stage $\geq 3, n(\%)$ & $67(8.9)$ & $158(8.9)$ & 0.95 & 1.01 (0.74 to 1.36$)$ & 0.88 (0.61 to 1.28$)$ \\
\hline Sepsis, n (\%) & $226(16.3)$ & $587(15.2)$ & 0.32 & 1.09 (0.92 to 1.29$)$ & 0.96 (0.80 to 1.14$)$ \\
\hline Composite outcome§, n (\%) & $495(35.7)$ & 1378 (35.6) & 0.97 & $1.00(0.88$ to 1.14$)$ & $1.03(0.83$ to 1.29$)$ \\
\hline
\end{tabular}

*Unadjusted and adjusted $\mathrm{OR}$ determined for $\mathrm{MgSO}_{4}$ versus $\mathrm{No}-\mathrm{MgSO}_{4}$.

†Adjusted for GA, sex, small for GA, outborn status, chorioamnionitis, mode of delivery, antenatal corticosteroid use and multiple gestation using multiple logistic regression models with GEE approach to account for the correlated data within each site (or site effects).

¥Intensive resuscitation defined as need for intubation and ventilation or chest compressions or epinephrine administration in the delivery room.

$\S$ Composite outcome defined as mortality or any major neonatal morbidity.

$\mathrm{GA}$, gestational age; IVH, intraventricular haemorrhage; $\mathrm{MgSO}_{4}$, magnesium sulfate; $\mathrm{NEC}$, necrotising enterocolitis; PVL, periventricular leukomalacia; ROP, retinopathy of prematurity; $\mathrm{GEE}$, generalised estimating equation. 
Table 4 Univariate and multivariate analyses of outcomes for infants 23-28 weeks gestational age

\begin{tabular}{|c|c|c|c|c|c|}
\hline & $\begin{array}{l}\mathrm{MgSO}_{4} \text { for fetal } \\
\text { neuroprotection }(n=731)\end{array}$ & 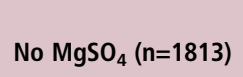 & p Value & $\begin{array}{l}\text { Unadjusted } \\
\text { OR }(95 \% \mathrm{CI})^{*}\end{array}$ & $\begin{array}{l}\text { Adjusted } \\
\text { OR }(95 \% \mathrm{Cl})^{*} \dagger\end{array}$ \\
\hline Intensive resuscitation $¥, \mathrm{n}(\%)$ & $451(62.4)$ & $1210(67.8)$ & $<0.01$ & $0.79(0.66$ to 0.94$)$ & $0.89(0.67$ to 1.18$)$ \\
\hline Death, n (\%) & $92(12.6)$ & $325(17.9)$ & $<0.01$ & $0.65(0.51$ to 0.85$)$ & $0.65(0.43$ to 1.00$)$ \\
\hline Bronchopulmonary dysplasia, n(\%) & $246(38.3)$ & $566(37.6)$ & 0.75 & $1.03(0.85$ to 1.25$)$ & $1.30(1.03$ to 1.65$)$ \\
\hline NEC stage $\geq 2, \mathrm{n}(\%)$ & $63(8.7)$ & $138(7.6)$ & 0.38 & $1.15(0.84$ to 1.57$)$ & $1.05(0.78$ to 1.42$)$ \\
\hline Grade 3 or 4 IVH or PVL, $\mathrm{n}(\%)$ & $150(21.3)$ & $380(22.0)$ & 0.69 & $0.96(0.77$ to 1.19$)$ & $1.11(0.77$ to 1.60$)$ \\
\hline ROP stage $\geq 3, \mathrm{n}(\%)$ & $64(12.4)$ & $153(12.9)$ & 0.79 & $0.96(0.70$ to 1.31$)$ & $0.86(0.59$ to 1.25$)$ \\
\hline Sepsis, n (\%) & $176(24.1)$ & $447(24.7)$ & 0.76 & $0.97(0.79$ to 1.18$)$ & $0.91(0.75$ to 1.11$)$ \\
\hline Composite outcome§, n (\%) & $418(57.2)$ & $1075(59.3)$ & 0.33 & $0.92(0.77$ to 1.09$)$ & $1.24(0.97$ to 1.61$)$ \\
\hline
\end{tabular}

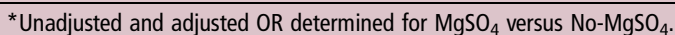

†Adjusted for GA, sex, small for GA, outborn status, chorioamnionitis, mode of delivery, antenatal corticosteroid use and multiple gestation using multiple logistic regression models with GEE approach to account for the correlated data within each site (or site effects).

fIntensive resuscitation defined as need for intubation and ventilation or chest compressions or epinephrine administration in the delivery room.

$\S$ Composite outcome defined as mortality or any major neonatal morbidity.

$\mathrm{GA}$, gestational age; IVH, intraventricular haemorrhage; $\mathrm{MgSO}_{4}$, magnesium sulfate; $\mathrm{NEC}$, necrotising enterocolitis; PVL, periventricular leukomalacia; ROP, retinopathy of prematurity;

$\mathrm{GEE}$, generalised estimating equation.

or death, no reduction was seen in the risk of death alone. ${ }^{4}$ 7-

11 Differences between this study population and the populations evaluated in the neuroprotection trials may account for this discrepancy in the odds of death. The pregnant women enrolled in the largest neuroprotection trial were randomised, on average, 1 week prior to delivery, with the potential for monitoring and optimisation of maternal-infant status prior to delivery. ${ }^{7}$ In this cohort study, some mothers may not have had the latency period between clinical presentation and delivery for optimisation of maternal-infant status, resulting in higher mortality in the unexposed group. In the subgroup analyses, only infants of 23-28 weeks GA had lower adjusted odds of death. The absence of this finding among infants 29-31 weeks GA may reflect an underpowered sample size given the very low mortality in this group, rather than a differential effect of the $\mathrm{MgSO}_{4}$ by GA.

While it is reassuring to observe that $\mathrm{MgSO}_{4}$ had no adverse effect on resuscitation requirements or neonatal outcomes, the retrospective nature of our study using a large database meant that the reasons for non-administration of $\mathrm{MgSO}_{4}$ were unknown. Given that this may be associated with an indication for preterm delivery and subsequent adverse outcomes, it may have introduced bias against the unexposed group. In particular, data on the time from maternal admission to delivery was not available, and thus non-administration of $\mathrm{MgSO}_{4}$ may reflect more precipitous delivery and reduced opportunity to optimise maternal-infant status. This potential bias is mitigated by several methodological and epidemiological aspects of this study: first, we excluded infants who were moribund at birth (designated to receive comfort care) or exposed to $\mathrm{MgSO}_{4}$ for other indications, as $\mathrm{MgSO}_{4}$ for fetal neuroprotection may have been withheld in these scenarios. ${ }^{1}$ Second, we adjusted for outborn status and ACS in the analyses. These factors likely represent, or are surrogates for, common reasons for non-administration of $\mathrm{MgSO}_{4}$. Finally, medical contraindications to $\mathrm{MgSO}_{4}$ (eg, magnesium hypersensitivity, renal impairment, heart block, myocardial damage and neuromuscular disorders) comprise the other reasons for non-administration, but are uncommon.

Additionally, the resuscitation requirements of the $\mathrm{MgSO}_{4}$-unexposed infants in this study are similar to that of other reported cohorts, suggesting that they were not appreciably more ill so as to comparatively make the $\mathrm{MgSO}_{4}-\mathrm{FN}$ group appear healthier. The $43.7 \%$ rate of delivery room intubation and ventilation in the $\mathrm{MgSO}_{4}$-unexposed group in this

Table 5 Univariate and multivariate analyses of outcomes for infants 29-31 weeks gestational age

\begin{tabular}{|c|c|c|c|c|c|}
\hline & $\begin{array}{l}\mathrm{MgSO}_{4} \text { for fetal } \\
\text { neuroprotection }(n=656)\end{array}$ & $\begin{array}{l}\mathrm{No} \mathrm{MgSO}_{4} \\
(n=2055)\end{array}$ & $\mathrm{p}$ Value & $\begin{array}{l}\text { Unadjusted } \\
\text { OR }(95 \% \mathrm{Cl})^{*}\end{array}$ & $\begin{array}{l}\text { Adjusted } \\
\text { OR }(95 \% \mathrm{Cl})^{*} \dagger\end{array}$ \\
\hline Intensive resuscitation $\neq, \mathrm{n}(\%)$ & $115(17.5)$ & $492(24.2)$ & $<0.01$ & 0.67 (0.53 to 0.83 ) & $0.82(0.57$ to 1.19$)$ \\
\hline Death, $n(\%)$ & $6(0.91)$ & $42(2.0)$ & 0.06 & 0.44 (0.18 to 1.05$)$ & $0.74(0.36$ to 1.51$)$ \\
\hline Bronchopulmonary dysplasia, n (\%) & $30(4.6)$ & $137(6.8)$ & 0.05 & 0.67 (0.44 to 0.99 ) & 0.73 (0.49 to 1.07$)$ \\
\hline NEC stage $\geq 2, \mathrm{n}(\%)$ & $20(3.0)$ & $59(2.9)$ & 0.81 & 1.06 (0.63 to 1.78$)$ & 1.03 (0.57 to 1.85$)$ \\
\hline Grade 3 or 4 IVH or PVL, $\mathrm{n}(\%)$ & $26(4.5)$ & $113(6.6)$ & 0.07 & 0.67 (0.43 to 1.04$)$ & 0.66 (0.40 to 1.06$)$ \\
\hline ROP stage $\geq 3, n(\%)$ & $3(1.3)$ & $5(0.8)$ & 0.56 & $1.53(0.36$ to 6.46$)$ & NA§ \\
\hline Sepsis, n (\%) & $50(7.6)$ & $140(6.8)$ & 0.48 & 1.23 (0.81 to 1.58$)$ & 1.23 (0.91 to 1.67$)$ \\
\hline Composite outcomeף, n (\%) & 77 (11.7) & $303(14.7)$ & 0.05 & 0.77 (0.59 to 1.01$)$ & 0.77 (0.59 to 1.01$)$ \\
\hline
\end{tabular}

*Unadjusted and adjusted OR determined for $\mathrm{MgSO}_{4}$ versus $\mathrm{No}_{-} \mathrm{MgSO}_{4}$.

†Adjusted for GA, sex, small for GA, outborn status, chorioamnionitis, mode of delivery, antenatal corticosteroid use and multiple gestation using multiple logistic regression models with GEE approach to account for the correlated data within each site (or site effects).

fIntensive resuscitation defined as need for intubation and ventilation or chest compressions or epinephrine administration in the delivery room.

§Unable to estimate due to few affected infants.

ПComposite outcome defined as mortality or any major neonatal morbidity.

$\mathrm{GA}$, gestational age; IVH, intraventricular haemorrhage; $\mathrm{MgSO}_{4}$, magnesium sulfate; $\mathrm{NEC}$, necrotising enterocolitis; PVL, periventricular leukomalacia; ROP, retinopathy of prematurity; $\mathrm{GEE}$, generalised estimating equation. 
study is similar to the rate of intubation and ventilation for all infants <31 weeks GA in the 2011 and $2012 \mathrm{CNN}$ censuses (43.7\% and $44.9 \%$, respectively). ${ }^{33}{ }^{34}$ Our rate is comparable with the Vermont Oxford Network rates of $47.8 \%$ and $46.9 \%$ for 2011 and 2012, respectively, among very low birth weight infants. $^{35}$

The strengths of this study include the use of a large population-level database with meticulous collection of outcomes, covariates measured in a standardised manner, a pragmatic setting and a large sample size of preterm neonates of 2331 weeks GA at birth. Importantly, this study included complete data on a large number of important antenatal confounders, permitting adjustment for these factors.

This study is limited by a lack of available database information during the study period to identify the indication for $\mathrm{MgSO}_{4}$ administration for a minority of infants. Five-hundred and forty-six infants were exposed to intrapartum $\mathrm{MgSO}_{4}$, but the indication was unknown at the time of data abstraction. The increased incidence of maternal hypertension in the $\mathrm{MgSO}_{4}-\mathrm{IU}$ group suggests that pre-eclampsia/eclampsia may have been the indication for $\mathrm{MgSO}_{4}$ in some of these cases. It is, nonetheless, reassuring that the $\mathrm{MgSO}_{4}-\mathrm{FN}$ and $\mathrm{MgSO}_{4}-\mathrm{IU}$ groups had similar resuscitation requirements and that when the $\mathrm{MgSO}_{4}-\mathrm{FN}$ group was considered alone, or in combination with the $\mathrm{MgSO}_{4}$-IU infants, the exposed infants did not have increased need for intensive resuscitation or adverse neonatal outcomes compared with unexposed infants.

The beneficial effects of intrapartum $\mathrm{MgSO}_{4}$ may occur within a therapeutic window, below which there may not be a measureable effect, within which there is probable benefit and above which there may be no additional value but potential for fetal toxicity. ${ }^{6}{ }^{36}$ Higher doses of $\mathrm{MgSO}_{4}$ and increased infant serum magnesium concentrations have been associated with higher mortality and a variable trend toward increased need for delivery room resuscitation. ${ }^{6} 246$ The SOGC recommends the use of a $4 \mathrm{~g}$ intravenous loading dose followed by a $1 \mathrm{~g} / \mathrm{h}$ maintenance infusion (maximum duration $24 \mathrm{~h}$, or total dose of $28 \mathrm{~g}$ ) to pregnant women at risk of preterm delivery at $<32$ weeks GA, ideally within $4 \mathrm{~h}$ before birth. ${ }^{1}$ In our study, data were not available regarding the dose or timing of $\mathrm{MgSO}_{4}$ administration or infant serum magnesium concentrations at the time of birth. Infants whose mother did not receive the recommended dose or whose most recent $\mathrm{MgSO}_{4}$ infusion concluded more than $4 \mathrm{~h}$ prior to birth, were included in the $\mathrm{MgSO}_{4}$ group. While we were unable to evaluate the relationship between $\mathrm{MgSO}_{4}$ dose, timing or serum magnesium concentration at birth and outcomes, this study provides a pragmatic evaluation of the population-level adverse effects and outcomes associated with intrapartum $\mathrm{MgSO}_{4}$ administration. Additional studies are needed to determine the optimal dose and timing of $\mathrm{MgSO}_{4}$ for fetal neuroprotection.

Our study captures subjects during a period of uptake of new knowledge, which is reflected in the low $\mathrm{MgSO}_{4}$ exposure rate in this study. The first Cochrane review recommending the use of $\mathrm{MgSO}_{4}$ for neuroprotection was published in February 2009, followed by publication of the Canadian guidelines in May 2011. A knowledge translation intervention is currently in progress. ${ }^{37}$ Surveillance studies should monitor the rate of $\mathrm{MgSO}_{4}$ exposure and may further clarify the factors that affect its administration.

\section{CONCLUSION}

The population-level administration of $\mathrm{MgSO}_{4}$ for fetal neuroprotection is not associated with an increased need for intensive delivery room resuscitation or adverse neonatal outcomes under contemporary resuscitation practices. While this supports the short-term safety of intrapartum $\mathrm{MgSO}_{4}$ administration in preterm infants, additional studies are needed to evaluate the population-level effectiveness of $\mathrm{MgSO}_{4}$ in reducing the targeted outcome of neuromotor impairment.

Acknowledgements We would like to thank Mr Xiang $Y$ Ye for statistical support and Dr Ruth Warre for editorial help, both from the Mother Infant Research Center, Mount Sinai Hospital, Toronto, during preparation of this manuscript.

Collaborators Site Investigators of the Canadian Neonatal Network: Prakesh S Shah (Director, Canadian Neonatal Network and Site Investigator, Mount Sinai Hospital, Toronto, Ontario); Wayne Andrews ( Janeway Children's Health and Rehabilitation Centre, St John's, NL); Keith Barrington (Sainte Justine Hospital, Montreal, QC); Wendy Yee (Foothills Medical Centre, Calgary, Alberta); Barbara Bullied (Everett Chalmers Hospital, Fredericton, New Brunswick, Canada); Rody Canning (Moncton Hospital, Moncton, NB); Ruben Alvaro (St. Boniface General Hospital, Winnipeg, Manitoba); Kimberly Dow (Kingston General Hospital, Kingston, Ontario); Michael Dunn (Sunnybrook Health Sciences Centre, Toronto, Ontario); Adele Harrison (Victoria General Hospital, Victoria, British Columbia, Canada); Andrew James (Hospital for Sick Children, Toronto, Ontario); Zarin Kalapesi (Regina General Hospital, Regina, Saskatchewan, Canada); Lajos Kovacs (Jewish General Hospital, Montreal, QC); Orlando da Silva (St. Joseph's Health Centre; London, Ontario); Douglas D. McMillan (IWK Health Centre, Halifax, Nova Scotia, Canada); Cecil Ojah (St. John Regional Hospital, St. John, New Brunswick, Canada); Abraham Peliowski/Khalid Aziz (Royal Alexandra Hospital, Edmonton, Alberta, Canada); Bruno Piedboeuf (Centre hospitalier universitaire de Quebec, Sainte Foy, QC); Patricia Riley (Montreal Children's Hospital, Montreal, QC); Daniel Faucher (Royal Victoria Hospital, Montreal, QC); Nicole Rouvinez-Bouali (Children's Hospital of Eastern Ontario, Ottawa, Ontario); Koravangattu Sankaran (Royal University Hospital, Saskatoon, Saskatchewan, Canada); Mary Seshia (Health Sciences Centre, Winnipeg, Manitoba); Sandesh Shivananda (Hamilton Health Sciences Centre, Hamilton, Ontario); Zenon Cieslak (Royal Columbian Hospital, New Westminster, British Columbia, Canada); Anne Synnes (Children's and Women's Health Centre of British Columbia, Vancouver, British Columbia, Canada); Herve Walti (Centre Hospitalier Universitaire de Sherbrooke, Fleurimont, QC), Shoo K. Lee (Chairman, Canadian Neonatal Network).

Contributors DEW: conceptualised and designed the study, revised the protocol, assembled the cohort, interpreted the data, drafted the initial manuscript, reviewed and revised the manuscript, and approved the final manuscript. SS and EA: conceptualised and designed the study, reviewed and revised the manuscript, and approved the final manuscript. WY: analysed and interpreted the data, reviewed and revised the manuscript and approved the final manuscript. AS: conceptualised the study, reviewed and revised the manuscript and approved the final manuscript. SKL: analysed and interpreted the data, reviewed and revised the manuscript and approved the final manuscript. PSS: conceptualised and designed the study, revised the protocol, interpreted the data, reviewed and revised the manuscript, and approved the final manuscript.

Funding This study was supported by a Team Grant to the Maternal-Infant Care Team from the Canadian Institutes of Health Research and funding support from the Ministry of Health and Long-term Care, Ontario, Canada, for infrastructure support to the Maternal-Infant Care Research Center which is the coordinating centre for the network. Additional funding was provided by individual participating hospitals.

Competing interests PSS is supported by an Applied Chair in Maternal and Child Health Services and Policy Research from the Canadian Institute of Health Research.

Ethics approval Research Ethics Board at each participating institution in the Canadian Neonatal Network.

Provenance and peer review Not commissioned; externally peer reviewed.

\section{REFERENCES}

1 Magee L, Sawchuck D, Synnes A, et al. SOGC Clinical Practice Guideline: magnesium sulphate for fetal neuroprotection. J Obstet Gynaecol Can 2011;33:516-29

2 American College of Obstetricians and Gynecologists, Society for Maternal-Fetal Medicine. Committee Opinion No. 455: magnesium sulfate before anticipated preterm birth for neuroprotection. Obstet Gynecol 2010;115:669-71.

3 Royal College of Obstetricians and Gynaecologists. Magnesium sulphate to prevent cerebral palsy following preterm birth: Scientific impact paper no. 29. 2011. http:// www.rcog.org.uk/files/rcog-corp/uploaded-files/SIP_No_29.pdf (accessed Dec 2013)

4 Marret S, Marpeau L, Zupan-Simunek V, et al. Magnesium sulphate given before very-preterm birth to protect infant brain: the randomised controlled PREMAG trial. BJOG 2007;114:310-18. 
5 Crowther CA, Hiller JE, Doyle LW, et al. Effect of magnesium sulfate given for neuroprotection before preterm birth: a randomized controlled trial. JAMA 2003;290:2669-76.

6 Mittendorf R, Dambrosia J, Pryde PG, et al. Association between the use of antenatal magnesium sulfate in preterm labor and adverse health outcomes in infants. Am J Obstet Gynecol 2002;186:1111-18.

7 Rouse DJ, Hirtz DG, Thom E, et al. A randomized, controlled trial of magnesium sulfate for the prevention of cerebral palsy. N Engl J Med 2008:359:895-905.

8 Magpie Trial Follow-Up Study Collaborative Group. The Magpie Trial: a randomised trial comparing magnesium sulphate with placebo for pre-eclampsia. Outcome for children at 18 months. BJOG 2007:114:289-99.

9 Doyle LW, Crowther CA, Middleton P, et al. Magnesium sulphate for women at risk of preterm birth for neuroprotection of the fetus. Cochrane Database Syst Rev 2009; (1):CD004661

10 Costantine MM, Weiner SJ. Effects of antenatal exposure to magnesium sulfate on neuroprotection and mortality in preterm infants: a meta-analysis. Obstet Gynecol 2009:114:354-64.

11 Conde-Agudelo A, Romero R. Antenatal magnesium sulfate for the prevention of cerebral palsy in preterm infants less than 34 weeks' gestation: a systematic review and metaanalysis. Am J Obstet Gynecol 2009;200:595-609.

12 Abbassi-Ghanavati M, Alexander JM, McIntire DD, et al. Neonatal effects of magnesium sulfate given to the mother. Am J Perinatol 2012;29:795-800.

13 Ramsey PS, Rouse DJ. Magnesium sulfate as a tocolytic agent. Semin Perinatol 2001:25:236-47.

14 Fawcett WJ, Haxby EJ, Male DA. Magnesium: physiology and pharmacology. $\mathrm{Br} J$ Anaesth 1999:83:302-20.

15 Ali A, Walentik C, Mantych GJ, et al. latrogenic acute hypermagnesemia after total parenteral nutrition infusion mimicking septic shock syndrome: two case reports. Pediatrics 2003;112:e70-2.

16 Lipsitz PJ. The clinical and biochemical effects of excess magnesium in the newborn. Pediatrics 1971;47:501-9.

17 Lipsitz PJ, English IC. Hypermagnesemia in the newborn infant. Pediatrics 1967:40:856-62.

18 Johnson LH, Mapp DC, Rouse DJ, et al. Association of cord blood magnesium concentration and neonatal resuscitation. J Pediatr 2012;160:573-7.

19 Davis DJ, Barrington KJ. Recommendations for neonatal surfactant therapy. Paediat Child Health 2005;10:109-16.

20 Morley CJ, Davis PG, Doyle LW, et al. Nasal CPAP or intubation at birth for very preterm infants. N Engl J Med 2008:358:700-8.

21 Finer NN, Carlo WA, Walsh MC, et al. Early CPAP versus surfactant in extremely preterm infants. N Engl J Med 2010;362:1970-9.
22 Vaucher YE, Peralta-Carcelen M, Finer NN, et al. Neurodevelopmental outcomes in the early CPAP and pulse oximetry trial. N Engl J Med 2012;367:2495-504.

23 Dunn MS, Jefferies AL. Recommendations for neonatal surfactant therapy -addendum. Paediatr Child Health 2012:17:137-8.

24 Basu SK, Chickajajur V, Lopez V, et al. Immediate clinical outcomes in preterm neonates receiving antenatal magnesium for neuroprotection. J Perinat Med 2012;40:185-9

25 Lee SK, McMillan DD, Ohlsson A, et al. Variations in practice and outcomes in the Canadian NICU network: 1996-1997. Pediatrics 2000;106:1070-9.

26 Canadian Neonatal Network Abstractor's Manual v2.0.0 Toronto: CNN; 2012. http://www.canadianneonatalnetwork.org (accessed Jan 2013).

27 Canadian Neonatal Resuscitation Program Steering Committee. Addendum to the 2006 NRP Provider Textbook: Recommendations for specific modifications in the Canadian context. 2010. http://www.cps.ca/images/nrp/NRP-Addendum.pdf (Accessed Dec 2013).

28 Papile LA, Burstein J, Burstein R, et al. Incidence and evolution of subependymal and intraventricular hemorrhage: a study of infants with birth weights less than 1,500 gm. J Pediatr 1978;92:529-34.

29 International Committee for the Classification of Retinopathy of Prematurity. The International Classification of Retinopathy of Prematurity revisited. Arch Ophthalmol 2005;123:991-9.

30 Bell MJ, Ternberg JL, Feigin RD, et al. Neonatal necrotizing enterocolitis. Therapeutic decisions based upon clinical staging. Ann Surg 1978;187:1-7.

31 Shennan AT, Dunn MS, Ohlsson A, et al. Abnormal pulmonary outcomes in premature infants: prediction from oxygen requirement in the neonatal period. Pediatrics 1988;82:527-32

32 Hanley JA, Negassa A, Edwardes MD, et al. Statistical analysis of correlated data using generalized estimating equations: an orientation. Am J Epidemiol 2003:157:364-75.

33 Shah PS, Lee SK, Yoon W, et al. The Canadian Neonatal Network Annual Report 2011. Canadian Neonatal Network, 2012. http://www.canadianneonatalnetwork. org (accessed Jan 2013).

34 Shah PS, Lee SK, Yoon EW, et al. The Canadian Neonatal Network Annual Report 2012. Canadian Neonatal Network, 2013. http://www.canadianneonatalnetwork. org (accessed Dec 2013).

35 Vermont Oxford Network of Very Low Birth Weight Infants. Burlington, VT: Vermont Oxford Network, 2013. [Data accessed from Nightingale Internet Reporting System on 17 December 2013].

36 Pryde PG, Mittendorf R. Using prophylactic, but not tocolytic, magnesium sulfate to reduce cerebral palsy related to prematurity: what dose, and what about infant mortality? J Perinat Med 2011;39:375-8.

37 Mag-CP study. https://www.cpn-rpc.org/MAGCP/home.aspx (accessed Mar 2013). 